\title{
Influence of radio frequency power on structure and ionic conductivity of LiPON thin films
}

\author{
ZONGQIAN HU*, DEZHAN LI and KAI XIE \\ College of Aerospace and Materials Engineering, National University of Defense Technology, \\ Changsha Hunan 410073, P R China
}

MS received 3 August 2007; revised 26 February 2008

\begin{abstract}
Lithium phosphorus oxynitride (LiPON) thin films as solid electrolytes were prepared by radio frequency magnetron sputtering of a $\mathrm{Li}_{3} \mathrm{PO}_{4}$ target in ambient nitrogen atmosphere. The influence of radio frequency (rf) power on the structure and the ionic conductivity of LiPON thin films has been investigated. The morphology, composition, structure and ionic conductivity of thin films were characterized by scanning electron microscopy, energy dispersive spectroscopy, X-ray diffraction, X-ray photoelectron spectroscopy and a.c. impedance measurement. It was found that ionic conductivity of LiPON thin films increases with $\mathrm{N}$ content in thin films. XPS measurements reveal that ionic conductivity also keeps relativity with the structure of thin films. Higher the $N_{\mathrm{t}} / N_{\mathrm{d}}$ ratio, higher will be the ionic conductivity of LiPON thin films. And both of them can be improved by increasing rf power from $1.5 \mathrm{~W} / \mathrm{cm}^{2}$ to $5.5 \mathrm{~W} / \mathrm{cm}^{2}$.
\end{abstract}

Keywords. LiPON; solid state electrolyte; thin films; radio frequency power.

\section{Introduction}

Since the first report of lithium phosphorus oxynitride (LiPON) thin films by Bates et al (1992), the growing interest in thin films has mainly focused on the investigation of the performance. Owing to a high ionic conductivity, LiPON thin films are widely applied in many electrochemical devices such as solid electrolytes, stable protective solid electrolyte interphase films and over layer for all-solid-state rechargeable lithium batteries (Bates et al 1994, 1995, 2000; Raffaelle et al 2000; Chung et al 2002, 2004; Joo et al 2003; West et al 2004; Zhao et al 2005).

In the previous work, it has been shown that the incorporation of nitrogen into phosphate glasses could increase the hardness, devitrification temperature, and resistance to water and salt solutions (Marchand 1983; Reidmeyer et al 1986; Larson and Day 1986). LiPON thin films exhibit a very low electronic conductivity, a relatively high ionic conductivity of $3.3 \times 10^{-6} \mathrm{~S} / \mathrm{cm}$ at room temperature, no phase change in wide temperature range, and a large stability electrochemical window voltage vs Li metal at room temperature (Bates et al 1993; Roh et al 2000). Therefore, with a better durability than sulfides and a better ionic conductivity than oxides, LiPON thin films could be used as a fine alternative to traditional sulfides and oxides glassy electrolytes in the all-solid-state rechargeable lithium batteries (Kennedy and Zhang 1988; Ménétrier et al 1992; Vinatier et al 1999).

*Author for correspondence (huzongqian@gmail.com)
A number of studies on the characteristics of LiPON thin films have been reported. However, the influence of deposition conditions (such as radio frequency (rf) power) on the structure and ionic conductivity of LiPON thin films draws less attention. In this study, we discover that a solid relationship exists between rf power and the structure of LiPON thin films, and the structure influences the ionic conductivity of LiPON thin films.

\section{Experimental}

\subsection{Thin film preparation}

LiPON thin films were deposited by radio frequency magnetron sputtering from a $\mathrm{Li}_{3} \mathrm{PO}_{4}$ target in ambient nitrogen atmosphere. $\mathrm{Li}_{3} \mathrm{PO}_{4}$ targets were prepared by uniaxial pressing of $\mathrm{Li}_{3} \mathrm{PO}_{4}$ powder $(99.95 \%)$ into a $60 \mathrm{~mm}$ diameter pellet and were sintered at $800^{\circ} \mathrm{C}$ for $6 \mathrm{~h}$. Two different substrates, Au-coated polyimide film and silicon wafer, were used for various characterization experiments. The base pressure was below $1 \times 10^{-3} \mathrm{~Pa}$. All targets were sputtered (at $13.56 \mathrm{MHz}$ ) at a constant forward power of $1.5 \mathrm{~W} / \mathrm{cm}^{2}$ to $5.5 \mathrm{~W} / \mathrm{cm}^{2}$. The substrate was placed at a distance of $6 \mathrm{~cm}$ away from the $\mathrm{Li}_{3} \mathrm{PO}_{4}$ target. Typically, the sputtering atmosphere was $\mathrm{N}_{2}$ $(99.999 \%)$ at a pressure of $1.5 \mathrm{~Pa}$. The film deposition was carried out with a continuous flow of the nitrogen atmosphere. Each deposition lasted for about $10 \mathrm{~h}$ and the substrate temperature was not controlled during deposition. 


\subsection{Characterization}

The thickness of LiPON thin films was determined using a Jeol JSM-6360LV scanning electron microscopy (SEM). The N/P ratio of thin films was determined by energy dispersive spectroscopy (EDS). The structure of LiPON thin films was analysed by X-ray diffraction (XRD) with a Rigata/max-C diffractometer $\left(\mathrm{CuK}_{\alpha}\right.$ radiation source, $\lambda=1.5406 \AA$ ). X-ray photoelectron spectroscopy (XPS) was used to determine the composition and structure of films deposited on a silicon wafer. The XPS survey scans were obtained on a Kratos Xsam 800 system with monochromatic $\mathrm{MgK}_{\alpha}(1253.6 \mathrm{eV})$ irradiation. To correct possible charge-up of thin films by X-ray irradiation, the binding energy was calibrated using $\mathrm{C}_{1 s}(284.6 \mathrm{eV})$ spectra. The asymmetric $\mathrm{N}_{1 s}$ peaks were resolved by the curve fitting technique, assuming the presence of two or three components in the respective regions. The composition of LiPON thin films was calculated from the resolved peak area. Ionic conductivity of LiPON thin films was obtained from an a.c. impedance measurement of $\mathrm{Au} / \mathrm{LiPON} / \mathrm{Au}$ sandwich structures fabricated on polyimide substrates where the Au electrodes were deposited by d.c. magnetron sputtering. The impedance for calculating the ionic conductivity was measured at room temperature. And the impedance for calculating the activation energy was measured with a $15^{\circ} \mathrm{C}$ increment from $20^{\circ} \mathrm{C}$ to $80^{\circ} \mathrm{C}$ with both increasing and decreasing temperatures. The impedance measurements were made in the frequency range from $1 \mathrm{~Hz} \sim 1 \mathrm{MHz}$.

\section{Results and discussion}

A typical XRD of a pure $\mathrm{Li}_{3} \mathrm{PO}_{4}$ target and a $\mathrm{LiPON}$ thin film deposited on silicon wafer are shown in figure 1. It

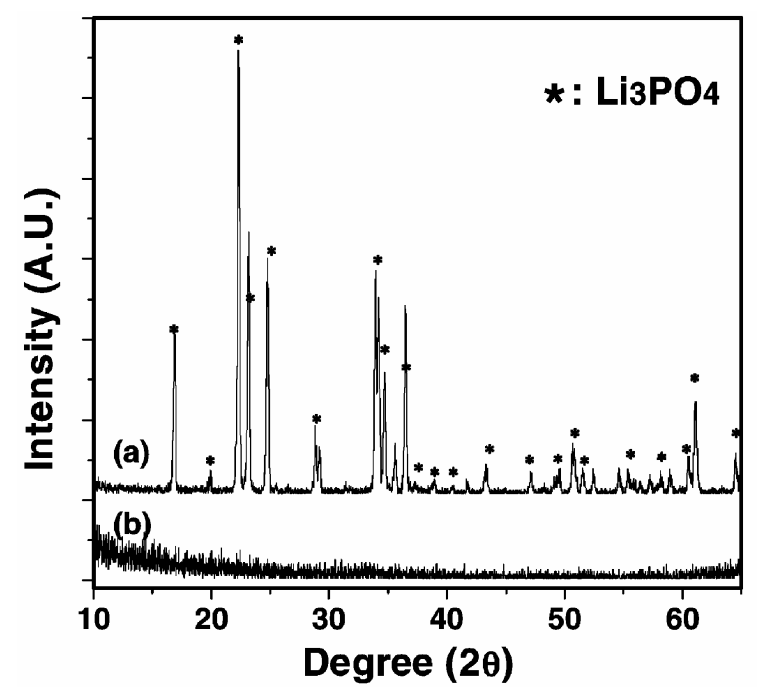

Figure 1. Typical X-ray diffraction patterns of (a) $\mathrm{Li}_{3} \mathrm{PO}_{4}$ target and (b) LiPON thin film. can be seen that the XRD of pure $\mathrm{Li}_{3} \mathrm{PO}_{4}$ target exhibits very intense diffraction peaks, which can be identified as diffractions of $\mathrm{Li}_{3} \mathrm{PO}_{4}$. However, there is no diffraction peaks in the XRD patterns of LiPON thin films deposited in $\mathrm{N}_{2}$ ambient. It suggests that our prepared LiPON thin films are amorphous.

Figure 2 is the SEM of the surface of a as-deposited LiPON thin film on the Pt current collector and the crosssection of $\mathrm{Pt} / \mathrm{LiPON} / \mathrm{Pt}$ sandwich structure. Figure $2 \mathrm{a}$ indicates that the deposited LiPON thin film is amorphous. There are no defects such as cracks and pinholes. Figure $2 \mathrm{~b}$ presents a cross-sectional view of the LiPON thin film. It shows that the thin film is well adherent to the Pt surface and the interface also does not show any indication of defects. The thickness of this film is about $3.2 \mu \mathrm{m}$. And the rate of film deposition for LiPON thin film can easily be calculated using sputtering time and thickness of thin films.
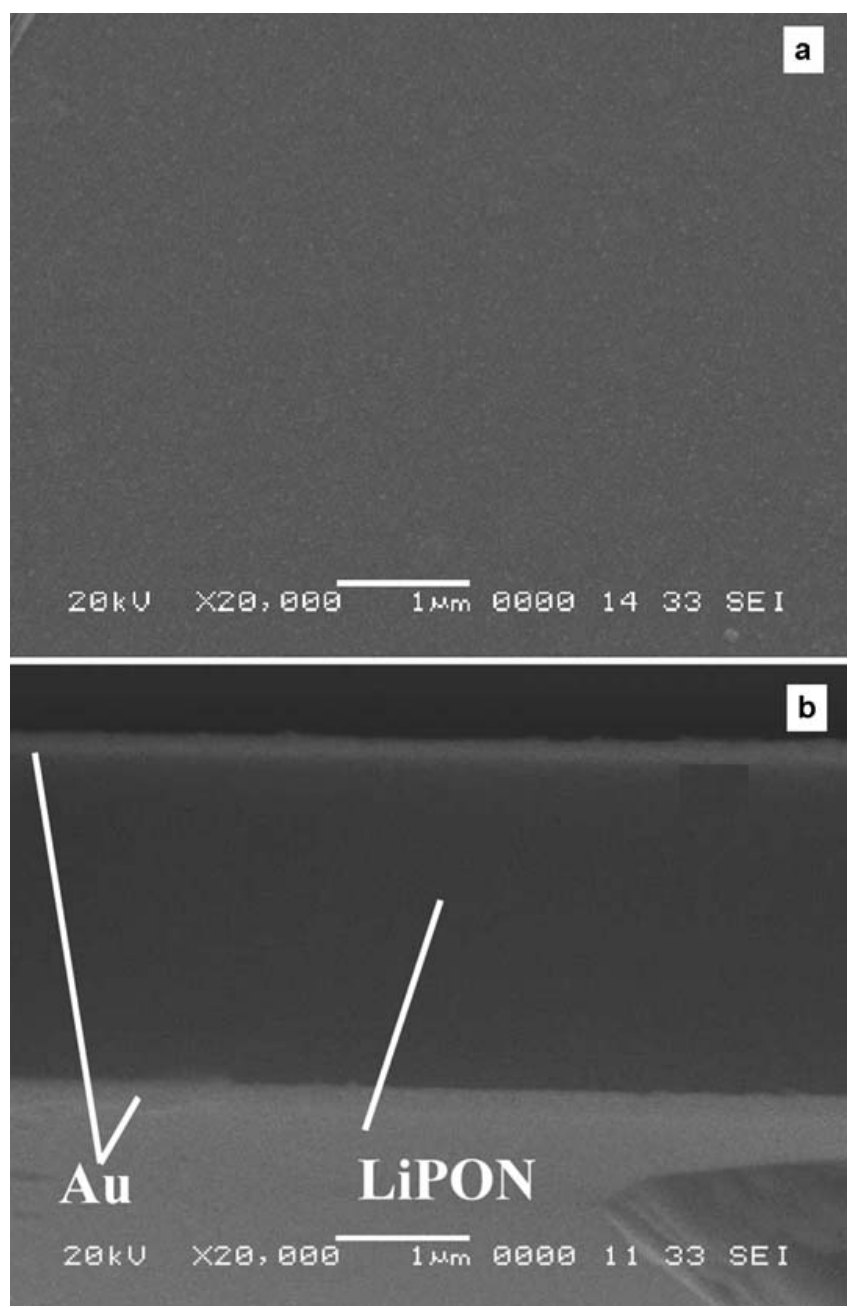

Figure 2. SEM images of a. surface of LiPON on Au film and b. cross-section of $\mathrm{Au} / \mathrm{LiPON} / \mathrm{Au}$ sandwich structure. (Deposition conditions: rf power is $5.5 \mathrm{~W} / \mathrm{cm}^{2}$, and nitrogen gas pressure is $1.5 \mathrm{~Pa}$ ) 
The effects of rf power on deposition rate and N/P ratio are shown in figure 3 . As usually observed, it can be found that the deposition rate of LiPON thin films increases with rf power. According to Hamon et al (2006), the N/P ratio decreases when rf power increases, but an opposite behaviour is observed in our research. Under the same rf power domain as in our study, the N/P ratio increases with rf power, which increases from 0.31 to 0.75 . This behaviour is the result of the following facts. In the case of a constant nitrogen pressure, the ionization of nitrogen is intensified with rf power. Because increasing rf power can cause the number and momentum of both the nitrogen ions and the sputtering particles to increase. Therefore, when rf power increases, the probability of the incorporation of $\mathrm{N}$ into $\mathrm{Li}_{3} \mathrm{PO}_{4}$ is enhanced, and the N/P ratio of thin films relatively increases.

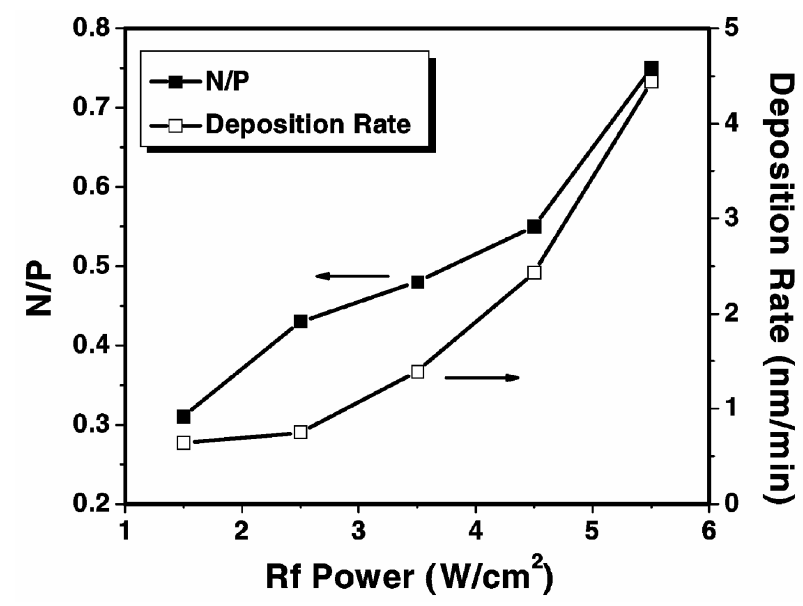

Figure 3. N/P ratio and deposition rate of LiPON thin films as a function of $\mathrm{rf}$ power.

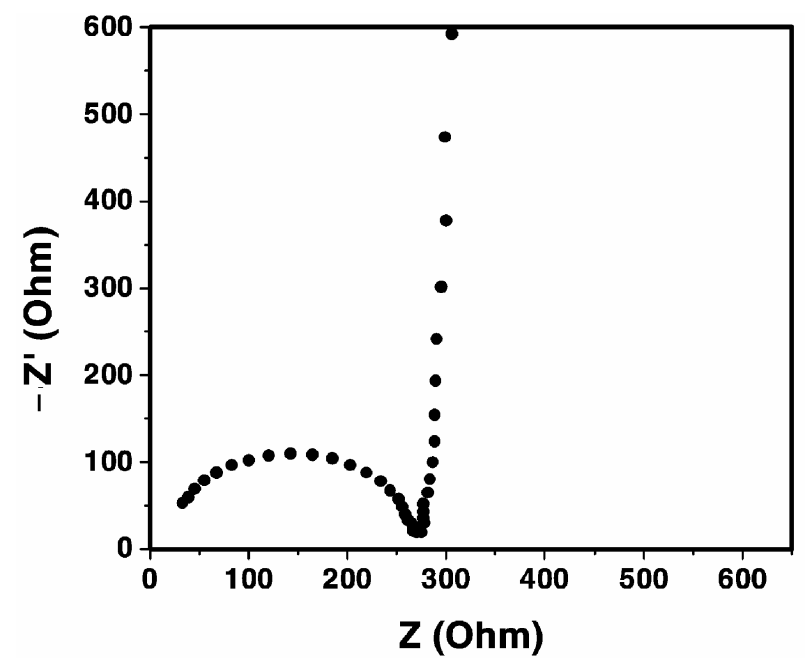

Figure 4. A Nyquist a.c. impedance plot of a LiPON thin film at room temperature. (Deposition conditions: $\mathrm{rf}$ power is $5.5 \mathrm{~W} / \mathrm{cm}^{2}$, and nitrogen gas pressure is $1.5 \mathrm{~Pa}$ ).
The ionic conductivity, $\sigma$, was calculated from $\sigma=$ $(1 / R) \times(d / A)$, where $d$ is the LiPON thin film thickness, $A$ the area of the metal contact, and $R$ the LiPON thin film resistance determined from the measured impedance by selecting the $Z$ value at the frequency at which $-Z^{\prime}$ goes through a local minimum (figure 4) (Yu et al 1997; Kim et al 2002). The impedance measurements for ionic conductivity of LiPON thin films were performed at $20^{\circ} \mathrm{C}$. The Arrhenius plot of ionic conductivity multiplied by absolute temperature, against reciprocal temperature, is shown in figure 5. The data is fitted to a straight line, indicating that the solid line is the result of a least squares fit of the Arrhenius equation (Yu et al 1997)

$$
\ln (\sigma)=\ln \left(\sigma_{\mathrm{o}}\right)-E_{\mathrm{a}} / k T,
$$

where $E_{\mathrm{a}}$ is the activation energy, $\sigma$ the ionic conductivity, $T$ the temperature and $k$ the Boltzmann constant.

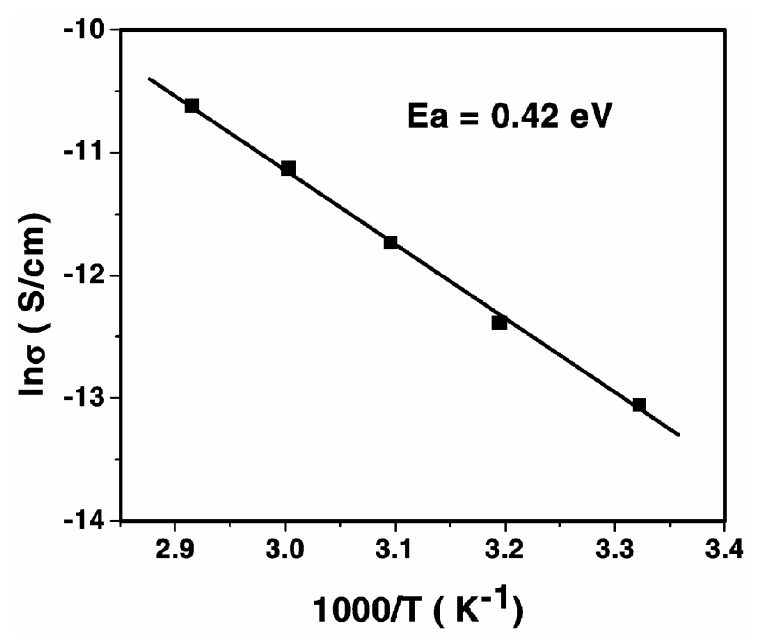

Figure 5. Typical Arrhenius behaviour of ionic conductivity vs temperature. (Deposition conditions: $\mathrm{rf}$ power is $5.5 \mathrm{~W} / \mathrm{cm}^{2}$, and nitrogen gas pressure is $1.5 \mathrm{~Pa}$ ).

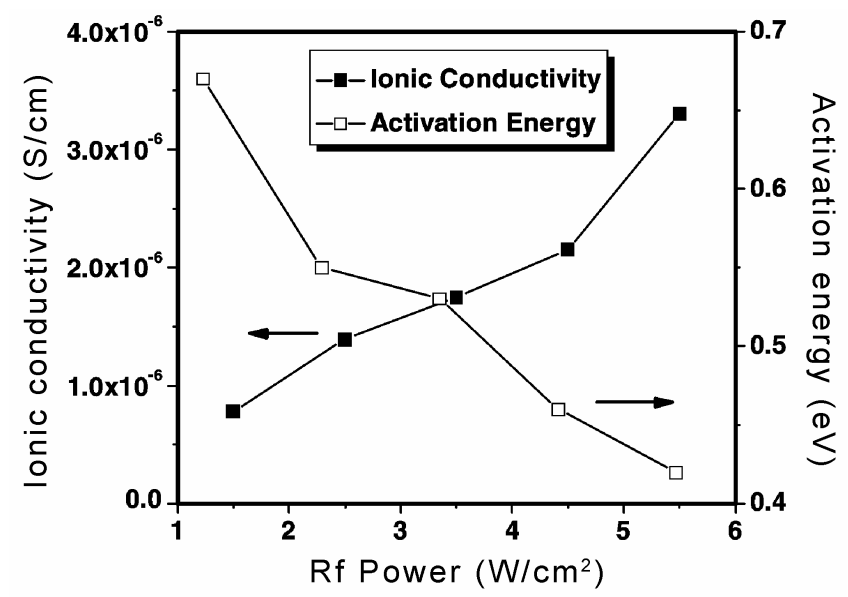

Figure 6. Ionic conductivity and activation energy of LiPON thin films as a function of $r f$ power. 
The influence of $\mathrm{rf}$ power on ionic conductivity and activation energy are shown in figure 6. It is found that ionic conductivity increases with $\mathrm{rf}$ power. And the ionic conductivity varies between $7.8 \times 10^{-7} \mathrm{~S} / \mathrm{cm}$ and $3.3 \times$ $10^{-6} \mathrm{~S} / \mathrm{cm}$. As expected, it can also be observed that the activation energy decreases from $0.67 \mathrm{eV}$ to $0.42 \mathrm{eV}$ when $r f$ power increases.

In spite of several studies, the reason for the positive correlation between ionic conductivity and N/P ratio of LiPON thin films is not yet clearly understood. In order to clearly exhibit the relationship between them, the ionic conductivity of thin films as a function of the N/P ratio is plotted in figure 7. Although the fact that all the deposition parameters are held constant, these trends are observed consistently. As shown in figure 7, the higher the $\mathrm{N} / \mathrm{P}$ ratio, the higher will be the ionic conductivity. The maximum ionic conductivity is $3.3 \times 10^{-6} \mathrm{~S} / \mathrm{cm}$ for $\mathrm{N} / \mathrm{P}=$ $0 \cdot 75$. It is different from the result of $3.3 \times 10^{-6} \mathrm{~S} / \mathrm{cm}$ for $\mathrm{N} / \mathrm{P}=0.46$ obtained by Bates et al (1993). Despite the discrepancies, the trend that the ionic conductivity increases with N/P ratio systematically is similar in both studies. The cause for it is the inevitable errors of the depositional system and the testing apparatus.

According to the equation (Roh et al 2000), $\sigma=$ (charge density) $\times$ (mobility), ionic conductivity is determined by the product of charge density and mobility. Therefore, there are two ways to increase the $\mathrm{Li}^{+}$ionic conductivity of LiPON thin films. One is increasing the $\mathrm{Li}^{+}$content in LiPON to increase charge carrier density. And the other is changing the bonding structure of the thin film to increase $\mathrm{Li}^{+}$mobility. However, the lithium content of thin film is nearly constant, which is irrespective of the $\mathrm{rf}$ power (Roh et al 2000). Thus, it appears that the second one is the main reason for the increase of ionic conductivity in relation to rf power. In order to analyse the structure information of the LiPON thin films, the XPS spectra for the thin films are obtained.

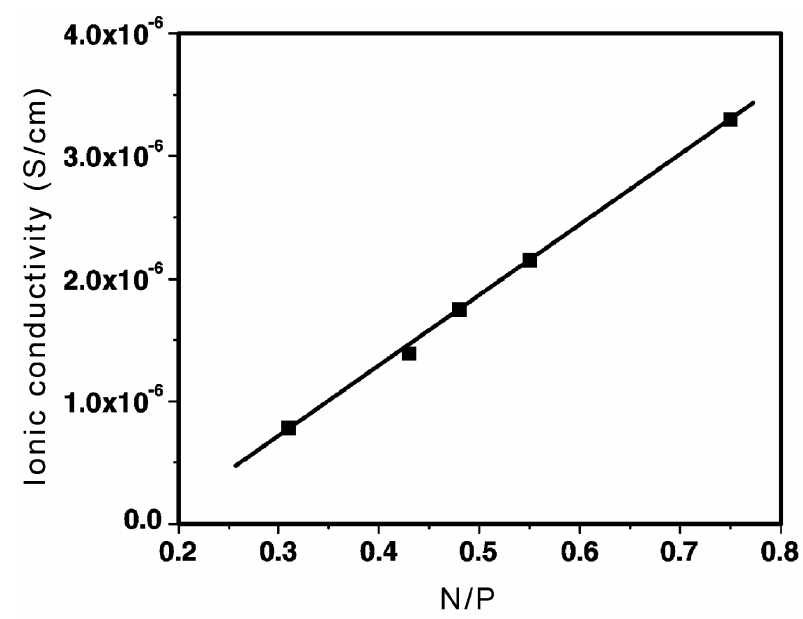

Figure 7. Ionic conductivity of LiPON thin films as a function of N/P ratio.
The XPS of $\mathrm{N}_{1 s}$ orbital was measured, and the XPS core level spectra of $\mathrm{N}_{1 s}$ for LiPON thin films deposited by sputtering at different $\mathrm{rf}$ powers $\left(1.5 \mathrm{~W} / \mathrm{cm}^{2}, 3.5 \mathrm{~W} / \mathrm{cm}^{2}\right.$, and $5.5 \mathrm{~W} / \mathrm{cm}^{2}$ ) are shown in figure 8 . In the $\mathrm{N}_{1 s}$ spectrum of LiPON thin films, an asymmetric peak is observed around $399 \mathrm{eV}$, which is resolved into two peaks. These
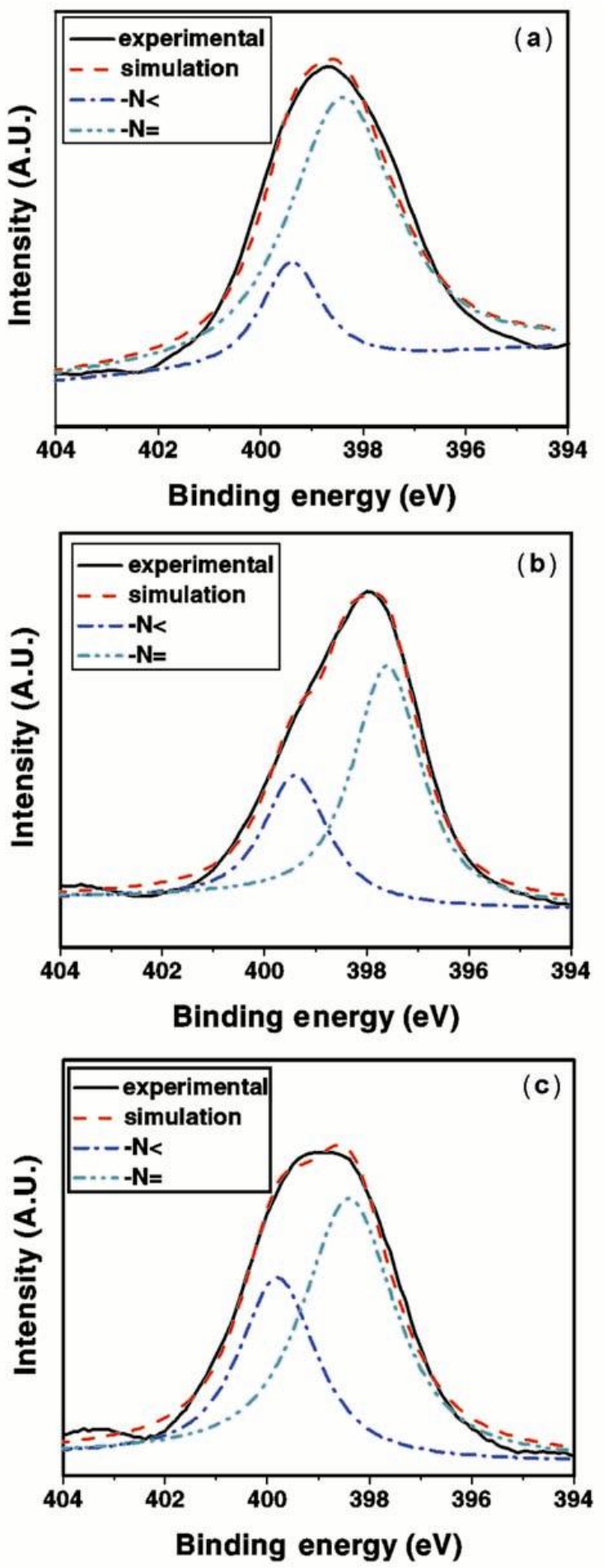

Figure 8. $N_{1 s}$ XPS spectrum of LiPON thin films deposited at (a) $1.5 \mathrm{~W} / \mathrm{cm}^{2}$, (b) $3.5 \mathrm{~W} / \mathrm{cm}^{2}$, and (c) $5.5 \mathrm{~W} / \mathrm{cm}^{2}$. 
peaks are assigned to the nitrogen bonds of doubly coordinated nitrogen $\mathrm{P}-\mathrm{N}=\mathrm{P}\left(N_{\mathrm{d}}\right)$ at $398.4 \mathrm{eV}$, and triply coordinated nitrogen $\mathrm{P}-\mathrm{N}<_{\mathrm{P}}^{\mathrm{P}}\left(N_{\mathrm{t}}\right)$ at $399.8 \mathrm{eV}$ (Marchand et al 1988). With rf power increasing from $1.5 \mathrm{~W} / \mathrm{cm}^{2}$ to $5.5 \mathrm{~W} / \mathrm{cm}^{2}$, the area of $\mathrm{P}-\mathrm{N}=\mathrm{P}$ structure unit decreases, while the area of $\mathrm{P}-\mathrm{N}<{ }_{\mathrm{P}}^{\mathrm{P}}$ structure unit increases. In the $N_{1 s}$ XPS spectrum, the larger area of the component indicates relative higher content of it in the structure. A quantitative measure of each bond was calculated from the area under the intensity curve corresponding to the assigned bond in the $N_{1 s}$ XPS spectra. The $N_{\mathrm{t}} / N_{\mathrm{d}}$ ratio determined from their respective areas in the spectrum is presented as a function of $\mathrm{rf}$ power in table 1 . It is found that the $N_{\mathrm{t}} / N_{\mathrm{d}}$ ratio increases with rf power, and ionic conductivity of LiPON thin films increases with the $N_{\mathrm{t}} / N_{\mathrm{d}}$ ratio. The maximum ionic conductivity is $3.3 \times 10^{-6} \mathrm{~S} / \mathrm{cm}$ for $N_{\mathrm{t}} / N_{\mathrm{d}}=0.63$, while the minimum one is $7.8 \times 10^{-7}$ $\mathrm{S} / \mathrm{cm}$ for $N_{\mathrm{t}} / N_{\mathrm{d}}=0 \cdot 16$. It means that a solid positive correlation exists between the ionic conductivity and the concentration of $\mathrm{P}-\mathrm{N}<{ }_{\mathrm{P}}^{\mathrm{P}}$ structure unit. The data shows that the increase in conductivity for LiPON thin films is due to the decrease in activation energy. Moreover, the concentration of $\mathrm{P}-\mathrm{N}<{ }_{\mathrm{P}}^{\mathrm{P}}$ structure unit quickly increases with lower rf power. And it increases slowly with rf power $>3.5 \mathrm{~W} / \mathrm{cm}^{2}$.

Table 1. Influence of $\mathrm{rf}$ power on the $N_{\mathrm{t}} / N_{\mathrm{d}}$ ratio, activation energy, and ionic conductivity of LiPON thin films.

\begin{tabular}{lccc}
\hline Rf power $\left(\mathrm{W} / \mathrm{cm}^{2}\right)$ & 1.5 & $3 \cdot 5$ & 5.5 \\
\hline$N_{\mathrm{t}} / N_{\mathrm{d}}$ ratio & 0.16 & 0.50 & 0.63 \\
Activation energy $(\mathrm{eV})$ & 0.67 & 0.53 & 0.42 \\
Ionic conductivity $\left(\times 10^{-6} \mathrm{~S} / \mathrm{cm}\right)$ & 0.78 & 1.8 & 3.3 \\
\hline
\end{tabular}
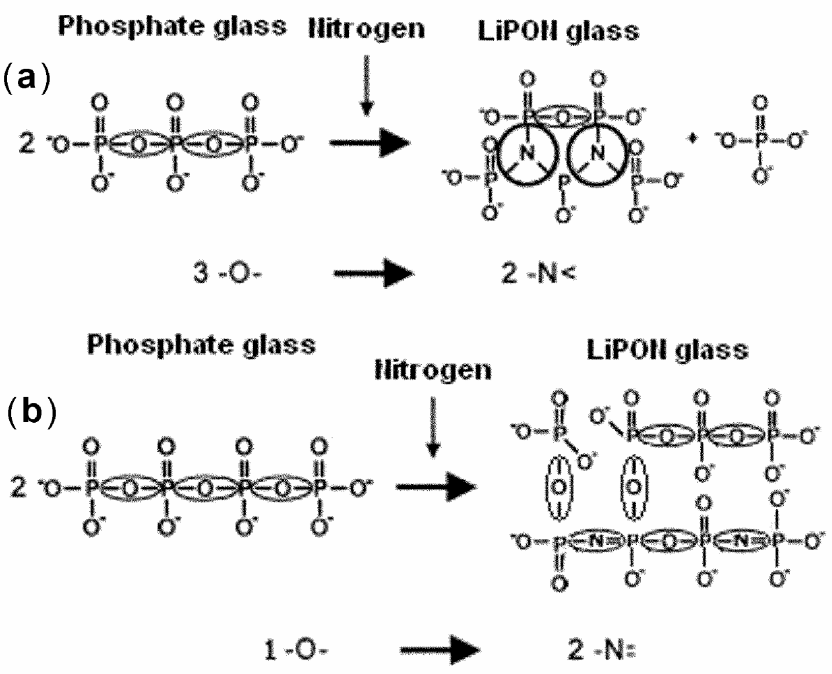

Figure 9. Partial structure of nitrided $\mathrm{Li}_{3} \mathrm{PO}_{4}$ glass with the incorporation of (a) $>\mathrm{N}-$ and (b) $-\mathrm{N}=$ resulting from the reaction of two adjacent phosphate chains with nitrogen.
The increase of ionic conductivity in LiPON thin films also can be attributed to the decreasing electrostatic energy as proposed by Unuma and Sakka (1987). Based on the structural model from Bunker et al (1987), every two P$\mathrm{N}<\mathrm{P}$ structural units created in the structure for three $\mathrm{P}-\mathrm{O}$ bonds are destroyed, while one $\mathrm{P}-\mathrm{O}$ bond has to be removed to form two $\mathrm{P}-\mathrm{N}=\mathrm{P}$ structural units (figure 9). Compared with two $\mathrm{P}-\mathrm{N}=\mathrm{P}$ structural units, two $\mathrm{P}-\mathrm{N}<\mathrm{P}$ structural units would remove two more $\mathrm{P}-\mathrm{O}$ bonds, which is less covalent than $\mathrm{P}-\mathrm{N}$ bond. Consequently, the contribution to the drop of electrostatic energy from $\mathrm{P}-$ $\mathrm{N}<\mathrm{P}$ structural unit is more than from $\mathrm{P}-\mathrm{N}=\mathrm{P}$ structural unit. In summary, it shows a strong evidence that $\mathrm{P}-\mathrm{N}<\mathrm{P}$ cross-linked structure unit is more responsible than $\mathrm{P}-$ $\mathrm{N}=\mathrm{P}$ structural unit for the increase in $\mathrm{Li}^{+}$mobility.

\section{Conclusions}

For the LiPON thin films electrolyte deposited by rf magnetron sputtering from a $\mathrm{Li}_{3} \mathrm{PO}_{4}$ target in ambient nitrogen atmosphere, the ionic conductivity of thin films increases with the increase of rf power from $1.5 \mathrm{~W} / \mathrm{cm}^{2}$ to $5.5 \mathrm{~W} / \mathrm{cm}^{2}$. The N/P ratio follows the same tendency with $\mathrm{rf}$ power in LiPON thin films.

Besides the $\mathrm{N}$ content, ionic conductivity of LiPON thin films also keeps the relativity with the structure of the thin films. It is observed that the contribution to the improvement of the ionic conductivity from $\mathrm{P}-\mathrm{N}<\mathrm{P}$ structure unit was far more than from $\mathrm{P}-\mathrm{N}=\mathrm{P}$ structure unit. And the $N_{\mathrm{t}} / N_{\mathrm{d}}$ ratio can be increased by increasing rf power up to $5.5 \mathrm{~W} / \mathrm{cm}^{2}$.

The maximum ionic conductivity of LiPON thin films is $3.3 \times 10^{-6} \mathrm{~S} / \mathrm{cm}$ when the bonding ratio of $N_{\mathrm{t}} / N_{\mathrm{d}}$ and $N / P$ are at a maximum. This condition was achieved for films deposited by sputtering with a $\mathrm{Li}_{3} \mathrm{PO}_{4}$ target at $5.5 \mathrm{~W} / \mathrm{cm}^{2}$.

\section{References}

Bates J B, Dudney N J, Gruzalski G R, Zuhr R A, Choudhury A, Luck C F and Robertson J D 1992 Solid State Ionics 53 647

Bates J B, Dudney N J, Gruzalski G R, Zuhr R A, Choudhury A and Luck C F 1993 J. Power Sources 43103

Bates J B, Gruzalski G R, Dudney N J, Luck C F and Yu X 1994 Solid State Ionics 70619

Bates J B, Dudney N J, Lubben D C, Gruzalski G R, Kwak B S, Yu X and Zuhr R A 1995 J. Power Sources 5458

Bates J B, Dudney N J, Neudecker B J, Hart F X, Jun H P and Hackney S A 2000 J. Electrochem. Soc. 14759

Bunker B C, Tallant D R, Luck C A, Kirkpatrick R J, Turner G L and Reidmeyer M R 1987 J. Am. Ceram. Soc. 70675

Chung K, Park J -G, Kim W -S, Sung Y -E and Choi Y -K 2002 J. Power Sources 112626

Chung K, Kim W -S and Choi Y -K 2004 J. Electroanal. Chem. 566263 
Hamon Y, Douard A, Sabary F, Marcel C, Vinatier P, Pecquenard B and Levasseur A 2006 Solid State Ionics 177 257

Joo K -H, Vinatier P, Pecquenard B, Levasseur A and Sohn H -J 2003 Solid State Ionics 16051

Kennedy J H and Zhang Z 1988 J. Electrochem. Soc. 135859

Kim B et al 2002 J. Power Source 109214

Larson R W and Day D E 1986 J. Non-Cryst. Solids 8887

Marchand R 1983 J. Non-Cryst. Solids 56173

Marchand R, Agliz D, Boukbir L and Quemerais A $1988 \mathrm{~J}$. Non-Cryst. Solids 10335

Ménétrier M, Estournes C, Levasseur A and Rao K J 1992 Solid State Ionics $\mathbf{5 3} 1208$
Raffaelle R P, Harris J D, Hehemann D, Scheiman D, Rybicki G and Hepp A F 2000 J. Power Sources 8952

Reidmeyer M R, Rajaram M and Day D E 1986 J. Non-Cryst. Solids $\mathbf{8 5} 186$

Roh N -S, Lee S D and Kwon H S 2000 Scr. Mater. 4243

Unuma H and Sakka S 1987 J. Mater. Sci. Lett. 6996

Vinatier P, Ménétrier M and Levasseur A 1999 Solid State Ionics 11635

West W C, Whitacre J F and Lim J R 2004 J. Power Sources 126134

Yu X H, Bates J B, Jellison G E and Harl F X 1997 J. Electrochem. Soc. 144524

Zhao S, Jia J, Wen J and Liu W 2005 Mater. Rev. 1938 